\title{
Can Insulin Resistance or Secretion be Programmed Earlier in Life?
}

\author{
Elaine de Oliveira*, Patricia Cristina Lisboa and Egberto Gaspar de Moura
}

Laboratory of Endocrine Physiology, Department of Physiological Sciences, Roberto Alcantara Gomes Biology Institute, State University of Rio de Janeiro, Rio de Janeiro, Brazil

\begin{abstract}
Diabetes and its complications occur at high rates in the world population. Several epidemiological studies have associated perinatal adversities, such as nutritional disturbances or diseases during gestation and lactation, with the development of insulin resistance or failure on insulin secretion in the adult progeny. Only recently the mechanism by which this phenomenon occurs is being delineated through series of experimental studies and implies epigenetics changes as a main initializing event. In this review, the authors give a comprehensive report of the different models of fetal and developmental programming that can result either in insulin resistance or insulin inappropriate secretion, with the possible mechanistic explanation for these alterations. The changes in the female workforce, which implies in profound nutritional and hormonal changes, exposure to endocrine disruptor or addictive compounds during gestation and lactation, including the reduction of lactation period creates conditions that, are obesogenic for their progenies, increasing the risk of type 2 diabetes mellitus. Finally, neonatal insults might be an important ethiopathogenic factor for the development of metabolic disturbances in adulthood, including obesity and diabetes, contributing to the considerable increase in chronic diseases incidence in society.
\end{abstract}

Keywords: Diabetes; Programming; Epigenetics; Reprogramming

\section{Diabetes Mellitus Development}

Generally, in the evolution of Type 2 Diabetes mellitus (T2D) there are two main steps. Insulin resistance is usually an initial step, which is compensated by hyperinsulinemia that can maintain normoglycemia. With the development of the disease hyperglycemia arises as a consequence of insulin secretion failure. This disease has genetic and environmental factors in its pathogenesis, and the latter may contributing more for the recent $\mathrm{T} 2 \mathrm{D}$ increase in epidemic proportion. It seems that environmental factors are more effective in the beginning of life, such as on the fetal period and in the newborn. Dorner et al. [1] already in 1975, was the first to associate a possible epigenetic transmission of diabetes mellitus that were more related to maternal than paternal influence, suggesting a stronger environmental link occurring through uterine milieu and lactation. Other authors had confirmed this association $[2,3]$.

\section{Developmental Programming Definition}

During periods of rapid growth such as pregnancy, lactation, and the period of spurt growth that occurs at puberty, the body appears to be highly sensitive to influences of environmental stimuli. An unfavorable environment can disturb the process of cell proliferation and differentiation, leading to changes in the normal developmental pathways of tissues and organs. Events occurring in these critical periods of life, such as pregnancy, lactation and adolescence, are able to modify the epigenetic pattern (DNA methylation, histone acetylation and uncoded RNA) that does not change the DNA sequence but are mitotically and transgenerationally inherited, establishing adaptive phenotypes to meet environmental demands in the long term. This process is considered an adaptive response to ensure the maintenance of critical functions of tissues and survival to the insult. This phenomenon is called metabolic programming and more recently, developmental plasticity, since the phenomenon seems to be more probabilistic than deterministic, as programming could make us believe $[4,5]$. If this adverse condition is not permanent, the individual becomes more susceptible to developing metabolic disorders in adulthood, modulating the physiological function and susceptibility to disease (Figure 1). This concept was proposed for the first time in the 90's from the XX century, in studies showing an association between adverse intrauterine conditions, for example, maternal malnutrition, with the later development of obesity, hypertension and cardiovascular disease [6]. The intrauterine programming is more prone to cause morphological, besides functional alteration. When the programming occurs after birth, especially in early infant, the programming effect is more functional and can be different from those observed during gestation, even when the insult is similar.

\section{Epidemiological Data - Geographical Differences}

Low Birth Weight (LBW) is associated with detrimental longterm metabolic consequences in humans. Several epidemiological studies have been investigating this new concept of the Developmental Origins of Health and Disease (DOHaD) hypothesis. The concept of developmental programming suggests that environmental insults during critical periods of development can trigger maladaptive changes in organ structure and function, thus increasing susceptibility to obesity, T2D, cardiovascular disease and metabolic syndrome in later life.

The aforementioned hypothesis emerged in the 80s of last century with studies in the UK, where was observed an association between LBW and obesity and diabetes mellitus at adulthood [7]. Curiously, Indian babies with LBW when compared with the UK babies were

${ }^{*}$ Corresponding author: Elaine de Oliveira, Departamento de Ciências Fisiológicas, Universidade do Estado do Rio de Janeiro, Instituto de Biologia Roberto Alcantara Gomes, Laboratório de Fisiologia Endócrina, Av. 28 de setembro, 87. Fundos, PAPC 5o. Andar, Rio de Janeiro, RJ, 20551-030, Brazil, Tel: (5521)-2868-8334; Fax: (5521)-2868-8029; E-mail: elainedeoliveir@pq.cnpq br, elainedeoliveir@yahoo.com.br

Received April 15, 2013; Accepted May 21, 2013; Published May 26, 2013

Citation: de Oliveira E, Lisboa PC, de Moura EG (2013) Can Insulin Resistance or Secretion be Programmed Earlier in Life? J Diabetes Metab S13: 002 doi:10.4172/2155-6156.S13-002

Copyright: (c) 2013 de Oliveira E, et al. This is an open-access article distributed under the terms of the Creative Commons Attribution License, which permits unrestricted use, distribution, and reproduction in any medium, provided the original author and source are credited. 


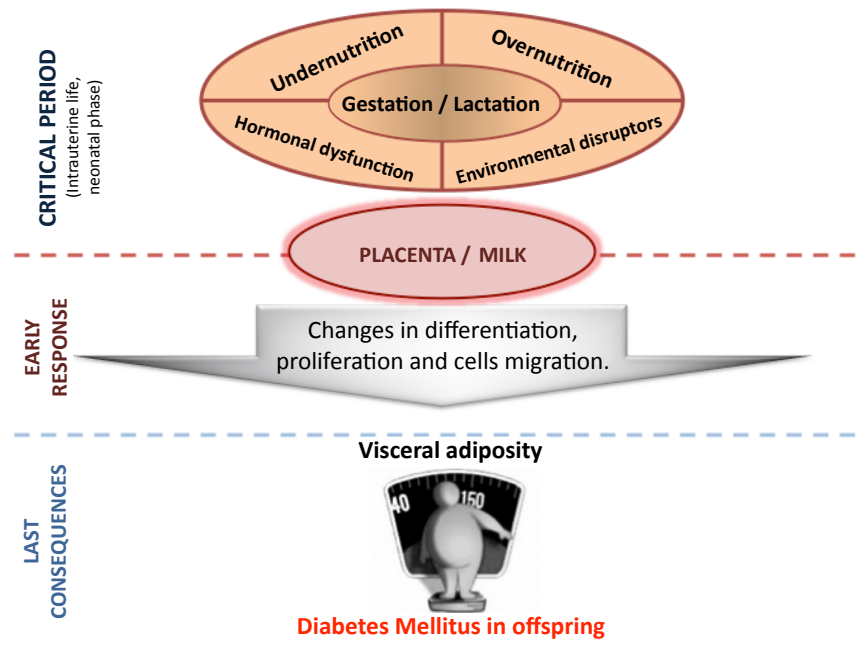

Figure 1: Schematic representation of the developmental programming process.

shorter, thinner but fatter [8]. Contrary to observe in western countries, where T2D patients had higher body mass index (BMI) and are obese, T2D patients in India were thinner but had higher central obesity [9]. Thus, for the same kind of imprinting condition (LBW), postnatal nutritional conditions during development may produce different programming effects.

Observations in children from mothers exposed to Dutch famine during the nazi siege in World War II shows that the programming of diabetes mellitus is dependent on the period of gestation when the mother is exposed to malnutrition. The babies from mothers exposed to famine during early pregnancy did not presented LBW but were prone to develop obesity when adults and those who were exposed in late pregnancy had a LBW, tendency to develop glucose intolerance, despite lower risk to develop obesity [10]. After WWII the nutritional conditions of Dutches improves. A similar nazi siege in Russia, with consequent famine to Leningrad citizens, failed to produce programming effects, probably because after the War the nutritional conditions did not have enough improvement [11].

Accelerated postnatal growth, or 'catch-up growth', following intra-uterine growth restriction (IUGR) has also been shown to be important in the programming of later metabolic disease risk as well as being an independent risk factor for overweight that can manifest as early as childhood [12]. Babies with LBW have a rapid catch-up growth and a high risk to develop obesity and insulin resistance. Some studies show that children with high birth weight as well as children with LBW have higher chances of developing obesity in adulthood, demonstrating that the nutritional imbalance, both for more and for less, is able to programming for metabolic disorders in adult life. In fact, it seems that more important than the birth weight are the maternal conditions, such as body weight gain during pregnancy and the quality of the maternal diet during pregnancy and lactation [13].

\section{Experimental Data - Models that Programs for Insulin Resistance or Deficient Insulin Secretion}

The development of experimental programming models contributed to the advancement in understanding the mechanisms involved in the alterations found in glucose homeostasis. Experimental models using maternal malnutrition, such as protein or energy malnutrition, placental uterine artery ligation or glucocorticoids exposure are able to replicate findings related to LBW. On the other hand, maternal over nutrition usually given a high fat diet reproduces typical effects of maternal obesity that causes dysfunction in insulin secretion and glucose intolerance in offspring [14]. Maternal diabetes is more complex, because can be also associated with high birth weight and childhood obesity, if moderate, but if severe can cause LBW [15] Interestingly, in most cases, offspring become obese in adulthood and therefore with a high risk of developing diabetes.

In rats, it has been shown that pancreatic islets and neurons are not fully mature at birth and that their development is completed in the immediate postnatal (suckling) period [16,17].

Some experiments show a programming effect increasing insulin sensitivity, such as maternal protein restriction during lactation, but most of the models of gestational or postnatal imprinting programs for insulin resistance and later insulin secretion failure with overt T2D. Below, were viewed some of the models more studied.

\section{Maternal malnutrition (energy vs. protein malnutrition)}

Nutrition has an important impact on some stages of life, especially during the fetal and early postnatal periods, having in some cases important consequences for health throughout the course of life. The growth of organs and tissues during the critical periods of development involves processes of differentiation, proliferation and migration of cells in organized structures. Although most of these processes occur during the intrauterine life, the neonatal phase is also considered a second important period for the physiological development. Thus, as it is well known that maternal malnutrition has a negative impact on the development of offspring, it is undisputable the merit of an adequate maternal nutrition during these stages of life.

Experimental studies with dietary restrictions on critical windows of development showed that depending of the type of diet restriction and the stage of life, in which the insult occur, the outcomes is different. Several models of maternal protein restriction were studied, some of them with drastic diet protein restriction ( $0 \%$ of protein) to moderate reduction (8 to 10\%). Most of those studies were performed during gestation, but some were done during gestation and lactation, and a more reduced number only during lactation.

Maternal under nutrition during pregnancy is associated with obesity, hyperinsulinemia and leptin resistance at adulthood [18]. Protein restriction in pregnant rats increases the risk of the offspring to develop higher blood pressure, obesity, hypertrophic adipocytes, higher insulin receptor expression and glucose metabolism alterations $[19,20]$. If protein restriction occurs only during lactation, the phenotype is different; the offspring shows low body weight, and higher insulin sensitivity in adult life [21-23]. It seems that this phase of higher insulin sensitivity turns in insulin resistance as the animal becomes older [24]

An insulin-resistant phenotype has been observed in both male and female adult rats born of dams fed a low-protein diet throughout pregnancy and lactation [24,25]. This was associated with impaired expression of key insulin-signalling proteins. Adipocytes isolated from low-protein offspring had significantly higher basal and insulinstimulated glucose uptakes than controls. This may be related to a threefold increase in insulin receptors in low-protein adipocytes. Consistent with these observed changes in glucose transport, adipocytes from low-protein animals had higher basal and insulinstimulated Insulin Receptor Substrate (IRS)-1-associated with phosphatidylinositol 3-kinase (PI 3-kinase) activities [26]. Recently, some studies, such as of Berends et al. [27], used cross-fostering to 
recuperate after birth, the pups whose mothers were protein restricted during gestation. The recuperated 3 months old male offspring had lower IRS-1, PI3K p110 $\beta$ and Akt phosphorylation in epididymal adipose tissue, but not significant changes in insulinemia or glycemia. By the contrary, the 3 months old offspring whose mothers were protein-restricted ( $0 \%$ protein) during the first ten days of lactation presented constitutively higher adipocyte levels of Akt, mTOR and GLUT4 that not respond to in vitro insulin administration [28].

Most of the experimental studies were done with rodents, mainly rats or some transgenic mice, and yet few studies with sheep that are more close to humans in relation to the type of gestation and lactation, since those animals usually produce only one offspring, instead of the 10-12 pups produced at each rat parturition. However, the results obtained with sheep are still controversial to characterize a true insulin resistance when maternal malnutrition occurs during pregnancy or lactation. George et al. [29] showed that the female offspring of energy malnourished ewes during gestation, develops when adults, higher insulin secretion, insulin resistance as well as lipid and glycogen liver accumulation. While, Costello et al. [30] showed an altered AKT and GLUT 4 in muscles of adult male offspring of undernourished mothers during pregnancy, but the glucose tolerance was normal, indicating an adaptive mechanism.

\section{Glucocorticoid exposure or maternal stress}

It is well described in literature that early life stress, i.e. exposure to glucocorticoid excess, induces important alterations in emotional and social functioning increasing the risk for the development of aggressive behaviors in animal models or human studies. The hypothalamicpituitary-adrenocortical (HPA) axis is one of the main pathways to respond to a stressor [31-34].

It is well known that glucocorticoids cause hyperglycemia by increasing insulin resistance and inhibiting glucose-stimulated insulin release from pancreatic beta cells [35]. Concerning the programming for metabolic and endocrine disorders, changes in the secretion of HPA axis and/or in glucocorticoid action are good candidate mechanism in animals and humans to link LBW with cardiometabolic risk factors, such as obesity, dyslipidemia, hypertension and glucose intolerance [36-38]. In fact, prenatal glucocorticoid administration to women at risk of preterm delivery has adverse long-term effects on offspring metabolic health, as hyperinsulinemia at 30 years old [39].

The postnatal manipulations, such as different forms of maternal deprivation have been investigated in rodents, including early handling, early deprivation and single or repeated maternal separation [40-49] which gave new insights in the effects of early life stressors on future alterations in HPA status and glucocorticoid action. In part, these effects seem to be mediated by epigenetically-induced changes in neuroendocrine function. Liu et al. [50] have shown that offspring from mothers with low maternal care (for eg., low licking and grooming) are more anxious, and have a lower corticosterone response to stress and a lower Glucocorticoid Receptor (GR) expression in the hippocampus at adulthood compared with offspring from mothers with high maternal care. By the contrary, neonatal stress, such as maternal separation and followed by needle puncture is associated with higher visceral fat mass and hyperinsulinemia. If those animals were mechanically tactile stimulated those programmed changes were prevented [51].

To date DNA methylation is the most common mechanism investigated, because methylation patterns are established during development. This issue will be better addressed in item 5.2 of this review [52]. Few studies in humans evidence that methylation of genes involved in glucocorticoid action are altered by the early life environment, and concerning these recent findings on epigenetic issues, more information has been published in several recent reviews [53-55].

\section{Maternal obesity and diabetes}

The prevalence of maternal obesity has risen in worldwide at an alarming rate in the last two decades. In the UK, around one in five pregnant women is obese while in the USA, approximately $64 \%$ of women of reproductive age are overweight and 35\% are obese [56]. Often, obese women give birth to large for gestational age babies, increasing the short-term risk complications during delivery as well as long-term influences on offspring health, either by direct effects of shared environmental or genetic factors or by programming effects [57].

In humans, maternal obesity has been associated with some longterm adverse health offspring outcomes during infancy, adolescence and even adulthood, including risk of obesity and other dysfunctions as insulin resistance, dyslipidemia and hypertension [58-60]. In fact, Catalano et al. [61] were the first group who demonstrated that the fetuses of obese mothers had greater insulin resistance than fetuses of lean women, but the mechanisms by which the programming effects of maternal obesity are mediated are less well understood, for eg, compared with maternal undernutrition.

Despite the mechanism of action is not yet completely known, evidence from experimental studies (with rodents and primates) has indicated that maternal obesity or fat diet exposure programs offspring for an increased risk of adult obesity and diabetes [62]. In mice, studies have shown that a maternal obesogenic diet (16\% fat, $33 \%$ sugar) for 6 weeks before mating and throughout pregnancy and lactation leads the 6 months-old offspring to higher adiposity, hypertension, hyperglycemia and hyperinsulinemia [63]. In addition, more recently it was reported that at 17 days of gestation, the fetuses from female mice fed with high fat diet ( $60 \mathrm{kcal} \%$ fat) for 4 weeks before mating and throughout pregnancy presented higher plasma glucose and insulin [64].

Gestational diabetes predisposes offspring to develop diabetes later in life [65] and this could have a transgeneration transmission independent of genetic causes [66,67]. The association of diabetes in offspring of diabetic mothers was twice than with diabetic fathers $[68,69]$. It is difficult to separate the genetic factors from the environmental factors, since the diabetic mothers have the genes that can be transmitted to the offspring. However, an elegant epidemiological study in Pima Indians community showed a 3.7fold higher prevalence of diabetes in the progeny of diabetic mothers after they develop diabetes than their siblings before their mothers developed diabetes [70].

In experimental models, gestational diabetes may induce pancreatic islet dysfunctions on the offspring and increase risk of diabetes in adult [71]. In rats, mild maternal diabetes is induced by administration of streptozotocin at the beginning of gestation and continuous glucose infusion at the last week of pregnancy. The fetus from these mothers develops pancreatic beta-cells hyperplasia and hyperinsulinemia, which explains why those fetus are macrossomic, but at adulthood despite beta-cells mass is normalized, in vivo and in vitro glucose-stimulated insulin secretion was deficient followed by glucose intolerance [72,73]. However, hyperglycemic mothers had microsomic newborns, which also presented beta-cells hyperplasia, but with marked degranulation, suggesting an early exhaustion of their secretory capacity, confirmed 
by hypoinsulinemia [74]. After birth there is a normalization of betacells mass, but when the animals grow older the beta-cells suffer hyperplasia, with a higher insulin response to glucose-stimulation and insulin resistance [75]. The female offspring transmit to their progeny (second generation) the same phenotype characteristics of the offspring of mild diabetic mothers, such as glucose intolerance and insulin secretion defect at adulthood, and the second generation transmit to a third generation. However, the male are incapable to transmit those phenotype to their progeny $[65,73]$.

\section{Overnutrition by early overfeed}

Overnutrition in rats is a well-characterized model for neonatal and childhood obesity. Overnutrition may be induced by reducing the litter size, which increases body fat content, triglycerides, insulin, leptin and glucose serum levels at weaning [76,77]. Early overfed rats' exhibit structural and functional hypothalamic changes, which impairs their response to both insulin [78] and leptin [79]. These changes may contribute to a higher risk of obesity-related diseases in adulthood. We recently, showed an altered liver oxidative stress and insulin resistance in this model [80]. Several studies have attributed this profile to neonatal hyperleptinemia, hyperinsulinemia and hyperglycaemia at weaning, which may cause a malprogramming throughout life. We failed to find any change in glycemia, insulinemia or leptinemia in the adult animal programmed by early neonatal overfeeding [81].

High carbohydrate milk formula until the time of weaning resulted in chronic hyperinsulinemia and adult-onset obesity (HC phenotype) in these rats supported by hypersecretory capacity of HC islets and hypothalamic alterations predisposing to hyperphagia [82]. Insulin secretion by pancreatic islets is under the control of peripheral (circulating blood glucose concentrations) and central Autonomic Nervous System (ANS) mechanisms. The Parasympathetic Nervous System (PNS) and the Sympathetic Nervous System (SNS) are the two opposing limbs of the ANS that extensively innervate the pancreas and regulate insulin secretion. The stimulatory effect of the PNS is exerted via acetylcholine, whereas the inhibitory effect of the SNS is exerted via norepinephrine. In vivo and in vitro studies on the insulin secretory capacity of islets from HC rats indicated an augmented response to cholinergic stimulation and a reduced sensitivity to adrenergic inhibition, suggesting that an altered ANS regulation contributes to the hypersecretory capacity of the HC islet cells [82].

\section{Nicotine or tobacco smoke exposure}

In early life, exposure to environmental chemicals seems to be one of the causes of world epidemic of obesity, acting as an obesogenic factor, and contributing to high levels of obesity and disorders closely associated with her, such as diabetes.

Recently, it has been shown that the critical windows are also sensitive to low doses of chemicals compounds. These agents, during the period of tissues organogenesis, are able to alter metabolic homeostasis, increasing the risk to develop obesity and diabetes [83].

The hypothesis is that lipophilic substances would be more diluted in obese individuals due to their greater content of fat mass compared to lean individuals. Adipose tissue gain over time furthers the dilution effect to lower serum levels independently of the chemical's elimination. The temporal dilution of chemical compounds by mass gain is important in children because their rapid growth. The metabolism of chemicals in obese is delayed and its half-lives is extended [84]. Thus, chemical concentration in blood may be lower in obese people due to dilution but it cumulative exposure may be higher because the extended half-life. Furthermore, as it is accumulated in the adipose tissue, it may exert toxicity due to their high tissue concentrations. Chemical's pharmacokinetics and pharmacodynamics seems to be altered in the obese, modifying for example the capacity of the peroxisome proliferator-activated receptor (PPAR)- $\gamma$ binding, which alters the process of adipocyte differentiation, and consequently adipose tissue metabolism.

Worldwide, around $40 \%$ of children are exposed to cigarette smoke at home, where $43 \%$ of them have at least one parent smoking [85] showing higher BMI and obesity already in childhood $[86,87]$.

Studies have shown the ability of maternal smoking to promote epigenetic changes in perinatal life and thus act as an important agent of programming including the development of glucose homeostasis dysfunction [88]. Perinatal maternal smoking increases the risk of obesity and diabetes in adult life [86-93].

Cigarette smoke exposure in early life influences significantly the infant development. The relationship between childhood smoke exposure and metabolic changes include the risk of developing atherosclerosis and diabetes in childhood. Epidemiological studies have demonstrated in children exposed to cigarette smoke a decrease in HDL-C, hyperleptinemia, increase in C-reactive protein and IL-6, and decreased adiponectin $[94,95]$. Similarly, smoke exposure is associated with the presence of autoantibodies to pancreatic islet cells, which can be the first step in the development of type 1 diabetes [96].

Experimental findings showed an association between fetal nicotine exposure and obesity, hypertension and glucose homeostasis change. In utero exposure to tobacco smoke from the partner may truly have an impact on the fetus, and is associated with obesity in women at adulthood [97].

Adult offspring from mothers exposed to nicotine during pregnancy and lactation is programmed not only to obesity but also to insulin resistance, glucose intolerance, cold intolerance, reduced spontaneous physical activity and high risk of cardiovascular disease $[93,97,98]$.

Nicotine exposure from conception until lactation results in permanent $\beta$-cell depletion and subsequent impaired glucose tolerance [97]. According to Holloway et al. [99], fetal and neonatal exposure to nicotine results in disorders in the offspring that are common to those observed in T2D, and that adverse glucose metabolism observed in rats exposed to nicotine during fetal and neonatal life, can influence the metabolic risk in subsequent generations.

As nicotine is transferred through breast milk [100], becomes important to know its effects on the infant's development when exposure occurs during lactation. To assess whether exposure to nicotine would impact in metabolism of offspring, if it happened only during lactation, our group decided to expose lactating rats to nicotine and to study the metabolism of their offspring when they were adult. We found no changes in fasting blood glucose or adiponectin in adult rats exposed to nicotine during lactation. However, we detected hyperinsulinemia and a higher insulin resistance index in these animals. Moreover, when we calculated the ratio of adiponectin to white adipose tissue mass, we observed lower adiponectin production per gram of adipose tissue, suggesting that a relative adiponectin insufficiency may be related to the development of insulin resistance in these animals [101], but it seems that the development of classical diabetes requires that nicotine exposure occurs in both gestation and lactation periods.

It is important to reinforce that not only the active smokers are 
exposed to developing smoking-related diseases. Environmental tobacco exposure (or second-hand exposure) is also associated with death for heart disease, lung cancer and other disorders. Cigarette smoke when inhaled by non-smokers can act on endocrine-metabolic system, and parameters related to metabolic syndrome have been associated with exposure to environmental tobacco exposure, such as hypertriglyceridemia, central obesity, decreased HDL-C and increased fasting serum insulin [102].

Rats and mice exposed to environmental tobacco smoke during lactation presented normoglycemia, hypoinsulinemia and lower HOMA- $\beta$ suggesting deficiency in pancreatic insulin secretion, which may be an explanation for the hypoinsulinemia [103-105]. This lower pancreatic insulin secretion is consequent of a reduction in mass of pancreatic $\beta$ cells that was previously observed in rats exposed to nicotine during pregnancy and lactation [97] or even an inhibitory effect of nicotine on pancreatic secretion of insulin [106]. Adult offspring exposed to cigarette smoke during lactation showed hyperglycemia and normoinsulinemia, suggesting the development of glucose intolerance associated with higher adiposity in these animals when adults, reinforcing the idea of a higher risk of metabolic syndrome development in individuals exposed to smoke cigarette [102,105].

\section{Mechanistic Explanation}

\section{Role of prolactin and leptin}

Therefore, both in excess as in deficiency of nutrients happens specific physiological responses that when occurring in critical periods of life will be able to modify epigenetic mechanisms and to act as metabolic imprinting factors. In metabolic programming models, the accumulation of adipose tissue appears to function as a determinant factor to development of glucose homeostasis disorders, especially if this accumulation occurs in the abdominal region. The mechanistic basis may involve an imbalance in the production of adipocytokines that modulate insulin sensitivity. In obesity, the adipose tissue produces more adipokines that cause insulin resistance, and less adipocytokine that improves insulin sensitivity. This imbalance in cytokine production has been proposed as a marker for diabetes mellitus, making the quantification of adipocytokine profile useful in clinical practice $[107,108]$. Thus, it is interesting to evaluate how adipocytokines, such as leptin, during the imprinting period of gestation or lactation can affect the hypothalamic and ANS neural development affecting the control of insulin secretion and action.

Our group showed that pups' leptin secretion during lactation can be affect by maternal malnutrition, showing lower levels at the beginning and mid-lactation and being higher at the end of lactation [109]. Then, we tested how leptin administration during this period of life could affect the future body composition and food intake and, we showed for the first time that leptin can program for higher body weight and food intake, when directly injected in the pups [110]. Later, independently Pinto et al. [111] and Bouret et al. [112] showed in elegant experiments that leptin can alter the hypothalamic neural plasticity if injected in $\mathrm{ob} / \mathrm{ob}$ mice, decreasing the number and functionality of NPY neurons and increasing POMC neurons. However, this effect was only possible in the neonatal period [112]. Leptin may be important for the normal proliferation of pancreatic $\beta$-cells in the neonatal period, because increases the viability of isolated rat pancreatic islets by suppressing apoptosis and increasing islet cell proliferation [113]. This could be the mechanistic basis, why leptin injected in this critical period of life could permanently alter food behavior, glucose homeostasis and insulin secretion. We showed that leptin injected on the pups during the first ten days of life caused a leptin surge at 30 days of life concomitantly with an insulin surge, and hypoadiponectinemia $[114,115]$. Then, those animals develop at adulthood hyperleptinemia and hyperinsulinemia, without changes in glycemia, but with hypertriglyceridemia. Trevenzoli et al. [116] showed in this model of neonatal hyperleptinemia that besides the hyperinsulinemia, the adult animals develop hypoadiponectinemia and liver microesteatosis. Vickers et al. [117] also found in male rats an effect of neonatal leptin treatment in increasing insulinemia in the adult animal. It seems that those effects are gender dependent, since in female neonatal leptin treatment seems to be protective to the effects of maternal under nutrition [118]. More recently, Itoh et al [119] showed glucose intolerance in 4 months old mice treated with leptin from postnatal day 5.5 to 10.5 . Curiously, if the secondary surge of leptin that occurs after weaning is blocked by leptin antibody, the programming effects of leptin on body weight, glucose homeostasis and hypertriglyceridemia is abolished [120]. However, the treatment of normal animals either with leptin antibody [120] or leptin antagonist [121] reproduces some of the alterations induced by leptin treatment during lactation. Thus, it seems that normal leptin levels at the neonatal period are necessary to a normal body weight and glucose homeostasis during development.

Malnutrition during lactation also is associated with low maternal prolactinemia [122]. Since prolactin is important for the maintenance of pancreatic beta-cell mass [123], we pharmacologically blocked the maternal prolactin at the last 3 days of lactation with bromocriptine and observed hyperglycemia and hypoadiponectinemia in the 180 days old offspring, despite normoinsulinemia [124]. The same kind of alteration on glucose homeostasis was observed when the suckling was interrupted by mechanical device, using a bandage in the mothers at the last 3 days of lactation [125].

\section{Epigenetic alterations - DNA methylation, histone acetylation and interference RNA}

In almost all countries, the epidemic of obesity has been rising inexorably since 1980 decade. In 1997, WHO accepted that this was a major public health problem [126]. Nowadays, interactions between genes and environment provide a promising explanation to the idea of future development of disease risk, as adult obesity and diabetes. In this sense, epigenetics, that is the study of functional modifications to the genome without altering the underlying DNA sequence, has emerged as a relevant field combining experimental, epidemiological, clinical, and public health research $[127,128]$.

Some populations, particularly in Latin America and Asia, are prone to developing central obesity, T2D and hypertension. Currently these features are being close related to epigenetic programming of gene expression in terms of metabolic/endocrine regulation that can induce a complex combination of adult health-related disorders [126]. In fact several studies strongly support the idea that epigenetic processes of gene expression patterns such as DNA methylation, histone modifications and small interference RNAs (siRNA or microRNAs), which are involved in chromatin remodeling, are affected by the environment and can display key roles in the developmental programming of adult disease $[126,128,129]$. DNA methylation is more stable and this change can be transferred to next generation, while histone modifications and microRNA are more self-limited alterations in gene transcriptionand it was not reported yet in transgenerational studies [130].

As schematized in Figure 2, different imprinting factors during a critical window of development, as gestation or lactation periods, can act through different epigenetic mechanisms. It appears that these 

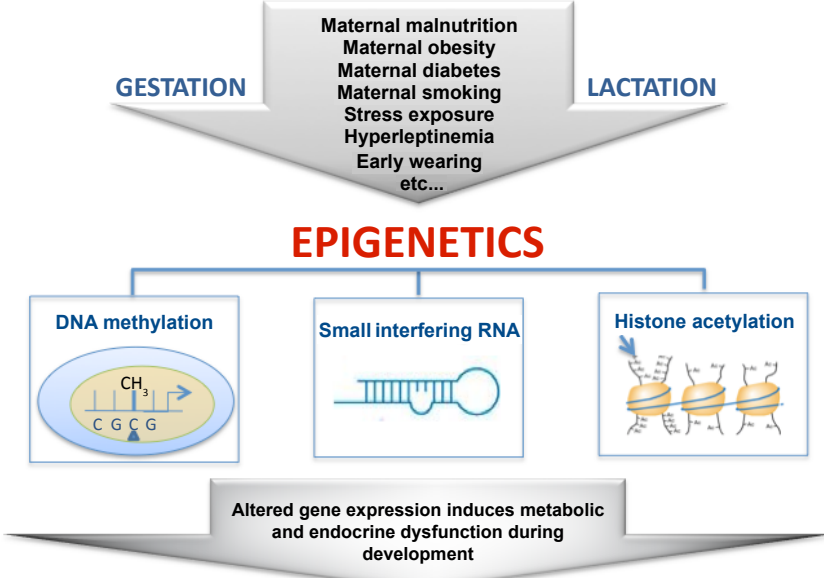

during

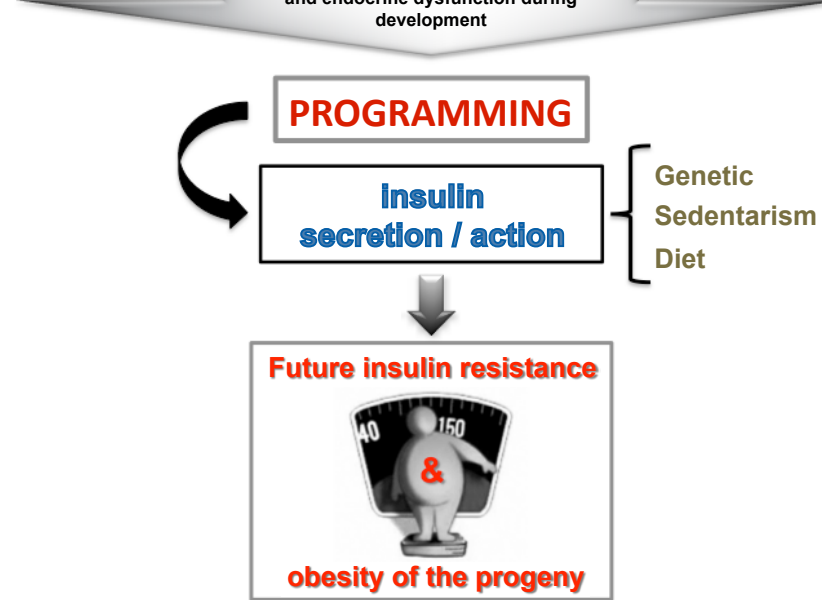

Figure 2: Epigenetic factors in insulin resistance development of adult offspring.

factors can activate the processes of DNA methylation and histones acetylation or deacetylation, or increase the levels of some siRNA, which may inhibit some genes related to normal insulin secretion and signaling, thereby affecting the developmental plasticity of the pancreas or insulin-dependent tissues, such as skeletal muscle, adipocyte and liver [5].

Epidemiological data of adults exposed to intrauterine energy restriction during the Dutch Hunger in World War II were the first to show DNA hypomethylation at the imprinted IGF2 region in mononuclear cells [131]. Those undernourished babies developed into overweight adults who had a higher cardiovascular risk, confirming the hypothesis that the early life nutritional status can induce epigenetic changes that persist throughout life and provide a mechanistic base for the $\mathrm{DOHaD}$ theory.

Sinclair et al. [132] provide the first experimental evidence that reductions in specific dietary lead to epigenetic alterations to DNA methylation in offspring, and change adult health-related phenotypes. In this study, it was showed that a restricted supply of vitamin B12, folate and methionine around conception to mature sheep changed the methylation status of $4 \%$ of CpG islands in the liver offspring and resulted in higher adiposity, lower lean mass, insulin resistance and higher blood pressure at adulthood. In addition, Indian evidence indicates that insulin resistance at birth is linked to LBW and increased body fat with selective vitamin B12 deficiency and abnormalities of one carbon pool metabolism potentially responsible and affecting $75 \%$ of Indians and many populations in the developing world [126].
Other issues related to epigenetic changes have been presented in recent reviews [133-135] as well as, particularly, concerning the recent advances in the epigenetic mechanisms in the development and function of the endocrine pancreas and type 2 diabetes programming [136-138].

\section{Reprogramming or Preventing Programmed Diabetes}

After a series of studies addressing the mechanisms involved in the metabolic programming phenomenon, currently the attention turns to strategies based in the knowledge about this mechanism and aimed controlling or preventing metabolic changes that underlie the programming, especially disorders in glucose metabolism and diabetes.

Both in humans as in animals, the caloric restriction, but not causing malnutrition, are capable of improving in a consistent form the insulin resistance [139]. In patients with overweight and insulin resistance, both calorie restriction and physical exercise reverse these disorders [140]. However, important changes in lifestyle seem to be a difficult practice in humans, especially when these new habits must be followed long-term. Therefore, new therapeutics ways, such as drugs and nutrients with bioactive properties, have been studied for obesity control and its metabolic disorders, especially T2D.

There is a wide range of bioactive components with aim to reprogramming or prevent the programmed insulin resistance or diabetes. Anti-oxidant compounds, rich in polyphenols such as resveratrol and yerba-mate, have shown beneficial effects on obesity and glycemic control, becoming a possible treatment option for T2D. Several studies have shown that yerba mate is capable of correcting serum glucose, triglycerides and LDL-C [141-143], improves significantly the glucose intolerance [144], even when combined with high-fat diets [145]. Another bioactive component that seems to have beneficial effects on metabolic alterations of obesity is resveratrol, a polyphenol extract mainly from red grapes. In experimental models, chronic treatment with resveratrol improves glucose tolerance [146], prevents obesity, and reduces oxidative stress and the risk of hypertension, dyslipidemia and liver steatosis in adult rats with programmed obesity [147]. The possible mechanism by which resveratrol improves glucose dysfunctions, seems be through increasing of GLUT4 translocation and enhancing of Akt phosphorylation, stimulating the glucose uptake by skeletal muscle [148]. These findings suggest an important role of these bioactive components in the management of obesity and its related disorders.

Literature shows the influence of dairy products in the energetic metabolism regulation. In patients, calcium-rich diet potentiates the beneficial effect of hypocaloric diet in decrease adiposity and improves the lipid profile, hypertension and insulin sensitivity [149]. Recently, our group showed that calcium supplementation is a good strategy to obesity and glucose intolerance treatment in early weaned rats and offspring from nicotine-exposed mothers [150,151].

Another possible strategy to prevent the development of glucose intolerance is to try to revert the hormonal alterations associated with malnutrition, such as hyperleptinemia or hypoprolactinemia or early weaning. In the first case, the use of leptin antibodies or antagonists may be promising $[120,121]$.

\section{Conclusions}

Notwithstanding, neonatal insults might be an important ethiopathogenic factor for the development of metabolic disorders in adult life, including obesity and diabetes, contributing to the 
considerable increase in chronic diseases incidence in society. Thus, it is important to know the epigenetics mechanisms that are responsible for the imprinting process and subsequent programming effects to design effective strategies to prevent or treat the alarming increase in diabetes prevalence.

\section{References}

1. Dörner G, Mohnike A, Steindel E (1975) On possible genetic and epigenetic modes of diabetes transmission. Endokrinologie 66: 225-227.

2. Martin AO, Simpson JL, Ober C, Freinkel N (1985) Frequency of diabetes mellitus in mothers of probands with gestational diabetes: possible maternal influence on the predisposition to gestational diabetes. Am J Obstet Gynecol 151: 471-475.

3. Harder T, Franke K, Kohlhoff R, Plagemann A (2001) Maternal and paternal family history of diabetes in women with gestational diabetes or insulindependent diabetes mellitus type I. Gynecol Obstet Invest 51: 160-164.

4. de Moura EG, Lisboa PC, Passos MC (2008) Neonatal programming of neuroimmunomodulation--role of adipocytokines and neuropeptides. Neuroimmunomodulation 15: 176-188

5. Gluckman PD, Hanson MA (2007) Developmental plasticity and human disease: research directions. J Intern Med 261: 461-471.

6. Barker DJ (2004) The developmental origins of adult disease. J Am Coll Nutr 23: 588S-595S.

7. Phillips DI, Barker DJ, Hales CN, Hirst S, Osmond C (1994) Thinness at birth and insulin resistance in adult life. Diabetologia 37: 150-154.

8. Yajnik CS, Lubree HG, Rege SS, Naik SS, Deshpande JA, et al. (2002) Adiposity and hyperinsulinemia in Indians are present at birth. J Clin Endocrinol Metab 87: 5575-5580.

9. Deurenberg P, Deurenberg-Yap M, Guricci S (2002) Asians are different from Caucasians and from each other in their body mass index/body fat per cent relationship. Obes Rev 3: 141-146.

10. Ravelli AC, van der Meulen JH, Michels RP, Osmond C, Barker DJ, et al. (1998) Glucose tolerance in adults after prenatal exposure to famine. Lancet 351: 173-177.

11. Stanner SA, Yudkin JS (2001) Fetal programming and the Leningrad Siege study. Twin Res 4: 287-292.

12. Fall CH, Pandit AN, Law CM, Yajnik CS, Clark PM, et al. (1995) Size at birth and plasma insulin-like growth factor-1 concentrations. Arch Dis Child 73: 287293.

13. Desai M, Beall M, Ross MG (2013) Developmental origins of obesity: programmed adipogenesis. Curr Diab Rep 13: 27-33.

14. Schack-Nielsen L, Michaelsen KF, Gamborg M, Mortensen EL, Sørensen T (2010) Gestational weight gain in relation to offspring body mass index and obesity from infancy through adulthood. Int J Obes (Lond) 34: 67-74.

15. Huang JS, Lee TA, Lu MC (2007) Prenatal programming of childhood overweight and obesity. Matern Child Health J 11: 461-473.

16. Grove KL, Allen S, Grayson BE, Smith MS (2003) Postnatal development of the hypothalamic neuropeptide $Y$ system. Neuroscience 116: 393-406.

17. Huang HP, Tsai MJ (2000) Transcription factors involved in pancreatic islet development. J Biomed Sci 7: 27-34.

18. Vickers MH, Breier BH, Cutfield WS, Hofman PL, Gluckman PD (2000) Fetal origins of hyperphagia, obesity, and hypertension and postnatal amplification by hypercaloric nutrition. Am J Physiol Endocrinol Metab 279: E83-87.

19. Bieswal F, Ahn MT, Reusens B, Holvoet P, Raes M, et al. (2006) The importance of catch-up growth after early malnutrition for the programming of obesity in male rat. Obesity (Silver Spring) 14: 1330-1343.

20. Ozanne SE, Hales CN (2002) Pre- and early postnatal nongenetic determinants of type 2 diabetes. Expert Rev Mol Med 4: 1-14.

21. Fagundes AT, Moura EG, Passos MC, Oliveira E, Toste FP, et al. (2007) Maternal low-protein diet during lactation programmes body composition and glucose homeostasis in the adult rat offspring. Br J Nutr 98: 922-928.

22. Fagundes AT, Moura EG, Passos MC, Santos-Silva AP, de Oliveira E, et al.
(2009) Temporal evaluation of body composition, glucose homeostasis and lipid profile of male rats programmed by maternal protein restriction during lactation. Horm Metab Res 41: 866-873.

23. Zambrano E, Bautista CJ, Deás M, Martínez-Samayoa PM, GonzálezZamorano M, et al. (2006) A low maternal protein diet during pregnancy and lactation has sex-and window of exposure-specific effects on offspring growth and food intake, glucose metabolism and serum leptin in the rat. J Physiol 571 221-230.

24. Fernandez-Twinn DS, Wayman A, Ekizoglou S, Martin MS, Hales CN, et al. (2005) Maternal protein restriction leads to hyperinsulinemia and reduced insulin-signaling protein expression in 21-mo-old female rat offspring. Am J Physiol Regul Integr Comp Physiol 288: R368-R373.

25. Petry CJ, Dorling MW, Pawlak DB, Ozanne SE, Hales CN (2001) Diabetes in old male offspring of rat dams fed a reduced protein diet. Int J Exp Diabetes Res 2: 139-143.

26. Ozanne SE, Nave BT, Wang CL, Shepherd PR, Prins J, et al. (1997) Poor fetal nutrition causes long-term changes in expression of insulin signaling components in adipocytes. Am J Physiol 273: E46-51.

27. Berends LM, Fernandez-Twinn DS, Martin-Gronert MS, Cripps RL, Ozanne SE (2012) Catch-up growth following intra-uterine growth-restriction programmes an insulin-resistant phenotype in adipose tissue. Int $\mathrm{J}$ Obes (Lond).

28. Garcia-Souza EP, da Silva SV, Félix GB, Rodrigues AL, de Freitas MS, et al. (2008) Maternal protein restriction during early lactation induces GLUT4 translocation and mTOR/Akt activation in adipocytes of adult rats. Am J Physio Endocrinol Metab 295: E626-636.

29. George LA, Zhang L, Tuersunjiang N, Ma Y, Long NM, et al. (2012) Early maternal undernutrition programs increased feed intake, altered glucose metabolism and insulin secretion, and liver function in aged female offspring. Am J Physiol Regul Integr Comp Physiol 302: R795-804.

30. Costello PM, Hollis LJ, Cripps RL, Bearpark N, Patel HP, et al. (2013) Lowe Maternal Body Condition During Pregnancy Affects Skeletal Muscle Structure and Glut-4 Protein Levels But Not Glucose Tolerance in Mature Adult Sheep. Reprod Sci

31. Levine S (2000) Influence of psychological variables on the activity of the hypothalamic-pituitary-adrenal axis. Eur J Pharmacol 405: 149-160.

32. Aisa B, Tordera R, Lasheras B, Del Río J, Ramírez MJ (2007) Cognitive impairment associated to HPA axis hyperactivity after maternal separation in rats. Psychoneuroendocrinology 32: 256-266.

33. Veenema AH (2009) Early life stress, the development of aggression and neuroendocrine and neurobiological correlates: what can we learn from animal models? Front Neuroendocrinol 30: 497-518.

34. Khulan B, Drake AJ (2012) Glucocorticoids as mediators of developmental programming effects. Best Pract Res Clin Endocrinol Metab 26: 689-700.

35. Reynolds RM, Walker BR (2003) Human insulin resistance: the role of glucocorticoids. Diabetes Obes Metab 5: 5-12.

36. Reynolds RM, Godfrey KM, Barker M, Osmond C, Phillips DI (2007) Stress responsiveness in adult life: influence of mother's diet in late pregnancy. J Clin Endocrinol Metab 92: 2208-2210.

37. Reynolds RM (2013) Glucocorticoid excess and the developmental origins of disease: two decades of testing the hypothesis--2012 Curt Richter Award Winner. Psychoneuroendocrinology 38: 1-11.

38. Reynolds RM, Labad J, Sears AV, Williamson RM, Strachan MW, et al. (2012) Glucocorticoid treatment and impaired mood, memory and metabolism in people with diabetes: the Edinburgh Type 2 Diabetes Study. Eur J Endocrino 166: 861-868.

39. Dalziel SR, Walker NK, Parag V, Mantell C, Rea HH, et al. (2005) Cardiovascular risk factors after antenatal exposure to betamethasone: 30-year follow-up of a randomised controlled trial. Lancet 365: 1856-1862.

40. Levine S, Huchton DM, Wiener SG, Rosenfeld P (1991) Time course of the effect of maternal deprivation on the hypothalamic-pituitary-adrenal axis in the infant rat. Dev Psychobiol 24: 547-558.

41. Meaney MJ, Aitken DH, Bodnoff SR, Iny LJ, Sapolsky RM (1985) The effects of postnatal handling on the development of the glucocorticoid receptor systems and stress recovery in the rat. Prog Neuropsychopharmacol Biol Psychiatry 9 : 731-734. 
42. Plotsky PM, Meaney MJ (1993) Early, postnatal experience alters hypothalamic corticotropin-releasing factor (CRF) mRNA, median eminence CRF content and stress-induced release in adult rats. Brain Res Mol Brain Res 18: 195-200.

43. Wigger A, Neumann ID (1999) Periodic maternal deprivation induces genderdependent alterations in behavioral and neuroendocrine responses to emotional stress in adult rats. Physiol Behav 66: 293-302.

44. van Oers HJ, de Kloet ER, Levine S (1997) Persistent, but Paradoxical, Effects on HPA Regulation of Infants Maternally Deprived at Different Ages. Stress 1 : 249-262.

45. Lehmann J, Feldon J (2000) Long-term biobehavioral effects of maternal separation in the rat: consistent or confusing? Rev Neurosci 11: 383-408.

46. Lehmann J, Russig H, Feldon J, Pryce CR (2002) Effect of a single maternal separation at different pup ages on the corticosterone stress response in adult and aged rats. Pharmacol Biochem Behav 73: 141-145.

47. Gutman DA, Nemeroff CB (2002) Neurobiology of early life stress: roden studies. Semin Clin Neuropsychiatry 7: 89-95.

48. Pryce CR, Feldon J (2003) Long-term neurobehavioural impact of the postnata environment in rats: manipulations, effects and mediating mechanisms. Neurosci Biobehav Rev 27: 57-71.

49. Rüedi-Bettschen D, Zhang W, Russig H, Ferger B, Weston A, et al. (2006) Early deprivation leads to altered behavioural, autonomic and endocrine responses to environmental challenge in adult Fischer rats. Eur J Neurosci 24: 2879-2893.

50. Liu D, Diorio J, Tannenbaum B, Caldji C, Francis D, et al. (1997) Maternal care, hippocampal glucocorticoid receptors, and hypothalamic-pituitary-adrenal responses to stress. Science 277: 1659-1662.

51. Haley S, Neff K, Gulliver K, Gough G, Slater H, et al. (2013) Mechanical-tactile stimulation (MTS) intervention in a neonatal stress model alters adult adipose tissue deposition and prevents hyperinsulinemia in male rats. Early Hum Dev 89: 387-392.

52. Filiberto AC, Maccani MA, Koestler D, Wilhelm-Benartzi C, Avissar-Whiting M, et al. (2011) Birthweight is associated with DNA promoter methylation of the glucocorticoid receptor in human placenta. Epigenetics 6: 566-572.

53. Crudo A, Petropoulos S, Moisiadis VG, Iqbal M, Kostaki A, et al. (2012) Prenatal synthetic glucocorticoid treatment changes DNA methylation states in male organ systems: multigenerational effects. Endocrinology 153: 3269-3283.

54. Drake AJ, McPherson RC, Godfrey KM, Cooper C, Lillycrop KA, et al. (2012). An unbalanced maternal diet in pregnancy associates with offspring epigenetic changes in genes controlling glucocorticoid action and fetal growth. Clin Endocrinol (Oxf) 77: 808-815.

55. Marsit CJ, Maccani MA, Padbury JF, Lester BM (2012) Placental 11-beta hydroxysteroid dehydrogenase methylation is associated with newborn growth and a measure of neurobehavioral outcome. PLoS One 7: e33794.

56. O'Reilly JR, Reynolds RM (2013) The risk of maternal obesity to the long-term health of the offspring. Clin Endocrinol (Oxf) 78: 9-16.

57. Catalano PM, Ehrenberg HM (2006) The short- and long-term implications of maternal obesity on the mother and her offspring. BJOG 113: 1126-1133.

58. Parsons TJ, Power C, Manor O (2001) Fetal and early life growth and body mass index from birth to early adulthood in 1958 British cohort: longitudinal study. BMJ 323: 1331-1335

59. Salsberry PJ, Reagan PB (2005) Dynamics of early childhood overweight Pediatrics 116: 1329-1338.

60. Sacks DA, Liu AI, Wolde-Tsadik G, Amini SB, Huston-Presley L, et al. (2006) What proportion of birth weight is attributable to maternal glucose among infants of diabetic women? Am J Obstet Gynecol 194: 501-507.

61. Catalano PM, Presley L, Minium J, Hauguel-de Mouzon S (2009) Fetuses of obese mothers develop insulin resistance in utero. Diabetes Care 32: 10761080

62. Dong M, Zheng Q, Ford SP, Nathanielsz PW, Ren J (2013) Maternal obesity, lipotoxicity and cardiovascular diseases in offspring. J Mol Cell Cardiol 55: 111116.

63. Samuelsson AM, Matthews PA, Argenton M, Christie MR, McConnell JM, et al. (2008) Diet-induced obesity in female mice leads to offspring hyperphagia, adiposity, hypertension, and insulin resistance: a novel murine model of developmental programming. Hypertension 51: 383-392.
64. Murabayashi N, Sugiyama T, Zhang L, Kamimoto Y, Umekawa T, et al. (2013) Maternal high-fat diets cause insulin resistance through inflammatory changes in fetal adipose tissue. Eur J Obstet Gynecol Reprod Biol .

65. Aerts L, Holemans K, Van Assche FA (1990) Maternal diabetes during pregnancy: consequences for the offspring. Diabetes Metab Rev 69: 179-197.

66. Alcolado JC, Laji K, Gill-Randall R (2002) Maternal transmission of diabetes Diabet Med 19: 89-98.

67. Pettitt DJ, Aleck KA, Baird HR, Carraher MJ, Bennett PH, et al. (1988) Congenital susceptibility to NIDDM. Role of intrauterine environment. Diabetes 37: 622-628.

68. Alcolado JC, Alcolado R (1991) Importance of maternal history of non-insulin dependent diabetic patients. BMJ 302: 1178-1180

69. Thomas F, Balkau B, Vauzelle-Kervroedan F, Papoz L (1994) Maternal effect and familial aggregation in NIDDM. The CODIAB Study. CODIAB-INSERMZENECA Study Group. Diabetes 43: 63-67.

70. Dabelea D, Hanson RL, Lindsay RS, Pettitt DJ, Imperatore G, et al. (2000) Intrauterine exposure to diabetes conveys risks for type 2 diabetes and obesity: a study of discordant sibships. Diabetes 49: 2208-2211.

71. Ding GL, Wang FF, Shu J, Tian S, Jiang Y, et al. (2012) Transgenerational glucose intolerance with Igf2/H19 epigenetic alterations in mouse islet induced by intrauterine hyperglycemia. Diabetes 61: 1133-1142.

72. Bihoreau MT, Ktorza A, Kervran A, Picon L (1986) Effect of gestational hyperglycemia on insulin secretion in vivo and in vitro by fetal rat pancreas. Am J Physiol 251: E86-91.

73. Gauguier D, Bihoreau MT, Picon L, Ktorza A (1991) Insulin secretion in adult rats after intrauterine exposure to mild hyperglycemia during late gestation. Diabetes 40: 109-114.

74. Kervran A, Guillaume M, Jost A (1978) The endocrine pancreas of the fetus from diabetic pregnant rat. Diabetologia 15: 387-393.

75. Aerts L, Sodoyez-Goffaux F, Sodoyez JC, Malaisse WJ, Van Assche FA (1988) The diabetic intrauterine milieu has a long-lasting effect on insulin secretion by B cells and on insulin uptake by target tissues. Am J Obstet Gynecol 159 . 1287-1292.

76. Plagemann A, Harder T, Rake A, Voits M, Fink H, et al. (1999) Perinatal elevation of hypothalamic insulin, acquired malformation of hypothalamic galaninergic neurons, and syndrome $x$-like alterations in adulthood of neonatally overfed rats. Brain Res 836: 146-155.

77. Rodrigues AL, de Moura EG, Passos MC, Dutra SC, Lisboa PC (2009) Postnata early overnutrition changes the leptin signalling pathway in the hypothalamicpituitary-thyroid axis of young and adult rats. J Physiol 587: 2647-2661.

78. Davidowa H, Plagemann A (2001) Inhibition by insulin of hypothalamic VMN neurons in rats overweight due to postnatal overfeeding. Neuroreport 12: 3201 3204.

79. Davidowa H, Plagemann A (2000) Decreased inhibition by leptin of hypothalamic arcuate neurons in neonatally overfed young rats. Neuroreport 11: 2795-2798.

80. Conceição EP, Franco JG, Oliveira E, Resende AC, Amaral TA, et al. (2013) Oxidative stress programming in a rat model of postnatal early overnutritionrole of insulin resistance. J Nutr Biochem 24: 81-87.

81. Conceição EP, Moura EG, Trevenzoli IH, Peixoto-Silva N, Pinheiro CR, et al. (2012) Neonatal overfeeding causes higher adrenal catecholamine content and basal secretion and liver dysfunction in adult rats. Eur $\mathrm{J}$ Nutr

82. Srinivasan M, Mahmood S, Patel MS (2013) Metabolic programming effects initiated in the suckling period predisposing for adult-onset obesity cannot be reversed by calorie restriction. Am J Physiol Endocrinol Metab 304: E486-494.

83. La Merrill M, Birnbaum LS (2011) Childhood obesity and environmenta chemicals. Mt Sinai J Med 78: 22-48.

84. Emond C, Birnbaum LS, DeVito MJ (2006) Use of a physiologically based pharmacokinetic model for rats to study the influence of body fat mass and induction of CYP1A2 on the pharmacokinetics of TCDD. Environ Health Perspect 114: 1394-1400.

85. World Health Organization (2009) WHO Report on the global tobacco epidemic - Implementing smoke-free environments. 7-28. Bloomberg Pilanthropies.

86. Braun JM, Daniels JL, Poole C, Olshan AF, Hornung R, et al. (2010) Prenata 
environmental tobacco smoke exposure and early childhood body mass index. Paediatr Perinat Epidemiol 24: 524-534.

87. Durmus B, Kruithof CJ, Gillman MH, Willemsen SP, Hofman A, et al. (2011) Parental smoking during pregnancy, early growth, and risk of obesity in preschool children: the Generation R Study. Am J Clin Nutr 94: 164-171.

88. Lisboa PC, de Oliveira E, de Moura EG (2012) Obesity and endocrine dysfunction programmed by maternal smoking in pregnancy and lactation. Front Physiol 3: 437

89. von Kries R, Toschke AM, Koletzko B, Slikker W Jr (2002) Maternal smoking during pregnancy and childhood obesity. Am J Epidemiol 156: 954-961.

90. Widerøe M, Vik T, Jacobsen G, Bakketeig LS (2003) Does maternal smoking during pregnancy cause childhood overweight? Paediatr Perinat Epidemiol 17 $171-179$

91. Goldani MZ, Haeffner LS, Agranonik M, Barbieri MA, Bettiol H, et al. (2007) Do early life factors influence body mass index in adolescents? Braz J Med Biol Res 40: 1231-1236

92. Koshy G, Delpisheh A, Brabin BJ (2011) Dose response association of pregnancy cigarette smoke exposure, childhood stature, overweight and obesity. Eur J Public Health 21: 286-291.

93. Somm E, Schwitzgebel VM, Vauthay DM, Camm EJ, Chen CY, et al. (2008) Prenatal nicotine exposure alters early pancreatic islet and adipose tissue development with consequences and the control of body weight and glucose metabolism later in life. Endocrinology 149: 6289-6299.

94. Nagel G, Arnold FJ, Wilhelm M, Link B, Zoellner I, et al. (2009) Environmental tobacco smoke and cardiometabolic risk in young children: results from a survey in south-west Germany. Eur Heart J 30: 1885-1893.

95. Hirata K, Yamano Y, Suzuki H, Miyagawa S, Nakadate T (2010) Passive smoking is associated with lower serum HDL-C levels in school children. Pediatr Int 52: 252-256

96. Skrodeniene E, Marciulionyte D, Padaiga Z, Jasinskiene E, SadauskaiteKuehne V, et al. (2008) Environmental risk factors in prediction of childhood prediabetes. Medicina (Kaunas) 44: 56-63.

97. Bruin JE, Kellenberger LD, Gerstein HC, Morrison KM, Holloway AC (2007) Fetal and neonatal nicotine exposure and postnatal glucose homeostasis: identifying critical windows of exposure. J Endocrinol 194: 171-178.

98. Somm E, Schwitzgebel VM, Vauthay DM, Aubert ML, Hüppi PS (2009) Prenata nicotine exposure and the programming of metabolic and cardiovascular disorders. Mol Cell Endocrinol 304: 69-77.

99. Holloway AC, Lim GE, Petrik JJ, Foster WG, Morrison KM, et al. (2005) Fetal and neonatal exposure to nicotine in Wistar rats results in increased beta cell apoptosis at birth and postnatal endocrine and metabolic changes associated with type 2 diabetes. Diabetologia 48: 2661-2666.

100. Luck W, Nau H (1987) Nicotine and cotinine concentrations in the milk of smoking mothers: influence of cigarette consumption and diurnal variation. Eur J Pediatr 146: 21-26.

101. de Oliveira E, Moura EG, Santos-Silva AP, Pinheiro CR, Lima NS, et al. (2010) Neonatal nicotine exposure causes insulin and leptin resistance and inhibits hypothalamic leptin signaling in adult rat offspring. J Endocrinol 206: 55-63.

102. Xie B, Palmer PH, Pang Z, Sun P, Duan H, et al. (2010) Environmental tobacco use and indicators of metabolic syndrome in Chinese adults. Nicotine Tob Res 12: 198-206.

103. Chen H, Hansen MJ, Jones JE, Vlahos R, Anderson GP, et al. (2007) Detrimental metabolic effects of combining long-term cigarette smoke exposure and high-fat diet in mice. Am J Physiol Endocrinol Metab 293: E1564-1571.

104. Chen H, Hansen MJ, Jones JE, Vlahos R, Anderson GP, et al. (2008) Longterm cigarette smoke exposure increases uncoupling protein expression but reduces energy intake. Brain Res 1228: 81-88.

105. Santos-Silva AP, Lisboa PC, Pinheiro CR, Maia LA, Peixoto-Silva N, et al. (2012) Maternal tobacco smoke exposure during lactation inhibits catecholamine production by adrenal medullae in adult rat offspring. Horm Metab Res 44: 550-554.

106. Yoshikawa H, Hellström-Lindahl E, Grill V (2005) Evidence for functional nicotinic receptors on pancreatic beta cells. Metabolism 54: 247-254.
107. Weiss R, Dziura J, Burgert TS, Tamborlane WV, Taksali SE, et al. (2004) Obesity and the metabolic syndrome in children and adolescents. $\mathrm{N}$ Engl Med 350: 2362-2374.

108. Yan WJ, Wu J, Mo J, Huang CW, Peng LW, et al. (2009) [Plasma levels of adiponectin and tumor necrosis factor-alpha in children with obesity] Zhongguo Dang Dai Er Ke Za Zhi 11: 47-50.

109. Teixeira C, Passos M, Ramos C, Dutra S, Moura E (2002) Leptin serum concentration, food intake and body weight in rats whose mothers were exposed to malnutrition during lactation. J Nutr Biochem 13: 493.

110. de Oliveira Cravo C, Teixeira CV, Passos MC, Dutra SC, de Moura EG, et al. (2002) Leptin treatment during the neonatal period is associated with higher food intake and adult body weight in rats. Horm Metab Res 34: 400-405.

111. Pinto S, Roseberry AG, Liu H, Diano S, Shanabrough M, et al. (2004) Rapid rewiring of arcuate nucleus feeding circuits by leptin. Science 304: 110-115.

112. Bouret SG, Draper SJ, Simerly RB (2004) Trophic action of leptin on hypothalamic neurons that regulate feeding. Science 304: 108-110.

113. Islam MS, Sjöholm A, Emilsson V (2000) Fetal pancreatic islets express functional leptin receptors and leptin stimulates proliferation of fetal islet cells. Int J Obes Relat Metab Disord 24: 1246-1253.

114. Toste FP, de Moura EG, Lisboa PC, Fagundes AT, de Oliveira E, et al. (2006) Neonatal leptin treatment programmes leptin hypothalamic resistance and intermediary metabolic parameters in adult rats. Br J Nutr 95: 830-837.

115. Passos MC, Toste FP, Dutra SC, Trotta PA, Toste FP, et al. (2009) Role of neonatal hyperleptinaemia on serum adiponectin and suppressor of cytokine signalling-3 expression in young rats. Br J Nutr 101: 250-256.

116. Trevenzoli IH, Rodrigues AL, Oliveira E, Thole AA, Carvalho L, et al. (2010) Leptin treatment during lactation programs leptin synthesis, intermediate metabolism, and liver microsteatosis in adult rats. Horm Metab Res 42: 483490.

117. Vickers MH, Gluckman PD, Coveny AH, Hofman PL, Cutfield WS, et al. (2008) The effect of neonatal leptin treatment on postnatal weight gain in male rats is dependent on maternal nutritional status during pregnancy. Endocrinology 149: 1906-1913.

118. Vickers MH, Gluckman PD, Coveny AH, Hofman PL, Cutfield WS, et al (2005) Neonatal leptin treatment reverses developmental programming. Endocrinology 146: 4211-4216.

119. Itoh H, Yura S, Sagawa N, Kanayama N, Konihi I; Hamamatsu Birth Cohort fo Mothers and Children (HBC) Study Team (2011) Neonatal exposure to leptin reduces glucose tolerance in adult mice. Acta Physiol (Oxf) 202: 159-164.

120. Trotta PA, Moura EG, Franco JG, Lima NS, de Oliveira E, et al. (2011) Blocking leptin action one week after weaning reverts most of the programming caused by neonatal hyperleptinemia in the adult rat. Horm Metab Res 43: 171-177.

121. Attig L, Solomon G, Ferezou J, Abdennebi-Najar L, Taouis M, et al. (2008) Early postnatal leptin blockage leads to a long-term leptin resistance and susceptibility to diet-induced obesity in rats. Int J Obes (Lond) 32: 1153-1160.

122. Lisboa PC, Passos MC, Dutra SC, Bonomo IT, Denolato AT, et al. (2006) Leptin and prolactin, but not corticosterone, modulate body weight and thyroid function in protein-malnourished lactating rats. Horm Metab Res 38: 295-299.

123. Amaral ME, Cunha DA, Anhê GF, Ueno M, Carneiro EM, et al. (2004) Participation of prolactin receptors and phosphatidylinositol 3-kinase and MAP kinase pathways in the increase in pancreatic islet mass and sensitivity to glucose during pregnancy. J Endocrinol 183: 469-476.

124. de Moura EG, Bonomo IT, Nogueira-Neto JF, de Oliveira E, Trevenzoli IH, et al. (2009) Maternal prolactin inhibition during lactation programs for metabolic syndrome in adult progeny. J Physiol 587: 4919-4929.

125. Lima Nda S, de Moura EG, Passos MC, Nogueira Neto FJ, Reis AM, et al. (2011) Early weaning causes undernutrition for a short period and programmes some metabolic syndrome components and leptin resistance in adult rat offspring. Br J Nutr 105: 1405-1413.

126. James WP (2008) The epidemiology of obesity: the size of the problem. Intern Med 263: 336-352.

127. Ozanne SE, Constância M (2007) Mechanisms of disease: the developmental origins of disease and the role of the epigenotype. Nat Clin Pract Endocrino Metab 3: 539-546. 
Citation: de Oliveira E, Lisboa PC, de Moura EG (2013) Can Insulin Resistance or Secretion be Programmed Earlier in Life? J Diabetes Metab S13: 002. doi:10.4172/2155-6156.S13-002

128. Gluckman PD, Hanson MA, Beedle AS (2007) Early life events and their consequences for later disease: a life history and evolutionary perspective. Am J Hum Biol 19: 1-19.

129. Guilloteau P, Zabielski R, Hammon HM, Metges CC (2009) Adverse effects of nutritional programming during prenatal and early postnatal life, some aspects of regulation and potential prevention and treatments. J Physiol Pharmacol 60: 17-35.

130. Hochberg Z, Feil R, Constancia M, Fraga M, Junien C, et al. (2011) Child health, developmental plasticity, and epigenetic programming. Endocr Rev 32 : 159-224.

131. Heijmans BT, Tobi EW, Stein AD, Putter H, Blauw GJ, et al. (2008) Persistent epigenetic differences associated with prenatal exposure to famine in humans. Proc Natl Acad Sci U S A 105: 17046-17049.

132. Sinclair KD, Allegrucci C, Singh R, Gardner DS, Sebastian S, et al. (2007) DNA methylation, insulin resistance, and blood pressure in offspring determined by maternal periconceptional B vitamin and methionine status. Proc Natl Acad Sci U S A 104: 19351-19356.

133. Waterland RA, Travisano M, Tahiliani KG, Rached MT, Mirza S (2008) Methy donor ementation prevents transgenerational amplification of obesity. Int $\mathrm{J}$ Obes (Lond) 32: 1373-1379.

134. Hussain N (2012) Epigenetic influences that modulate infant growth, development, and disease. Antioxid Redox Signal 17: 224-236.

135. Sookoian S, Gianotti TF, Burgueño AL, Pirola CJ (2013) Fetal metabolic programming and epigenetic modifications: a systems biology approach. Pediatr Res 73: 531-542.

136. Berends LM, Ozanne SE (2012) Early determinants of type-2 diabetes. Best Pract Res Clin Endocrinol Metab 26: 569-580.

137. Vaag AA, Grunnet LG, Arora GP, Brøns C (2012) The thrifty phenotype hypothesis revisited. Diabetologia 55: 2085-2088.

138. Sandovici I, Hammerle CM, Ozanne SE, Constância M (2013) Developmental and environmental epigenetic programming of the endocrine pancreas: consequences for type 2 diabetes. Cell Mol Life Sci 70: 1575-1595.

139. Heilbronn LK, de Jonge L, Frisard MI, DeLany JP, Larson-Meyer DE, et al. (2006) Effect of 6-month calorie restriction on biomarkers of longevity, metabolic adaptation, and oxidative stress in overweight individuals: a randomized controlled trial. JAMA 295: 1539-1548.

140.Larson-Meyer DE, Heilbronn LK, Redman LM, Newcomer BR, Frisard MI, et al. (2006) Effect of calorie restriction with or without exercise on insulin sensitivity, beta-cell function, fat cell size, and ectopic lipid in overweight subjects. Diabetes Care 29: 1337-1344.

141.Pomilio AB, Trajtemberg S, Vitale AA (2002) High-performance capillary electrophoresis analysis of mate infusions prepared from stems and leaves of Ilex paraguariensis using automated micellar electrokinetic capillary chromatography. Phytochem Anal 13: 235-241.

142. Mosimann AL, Wilhelm-Filho D, da Silva EL (2006) Aqueous extract of Ilex paraguariensis attenuates the progression of atherosclerosis in cholesterolfed rabbits. Biofactors 26: 59-70.

143. Pang J, Choi Y, Park T (2008) llex paraguariensis extract ameliorates obesity induced by high-fat diet: potential role of AMPK in the visceral adipose tissue. Arch Biochem Biophys 476: 178-185.

144. Lima ND, Franco JG, Peixoto-Silva N, Maia LA, Kaezer A, et al. (2013) Ilex paraguariensis (yerba mate) improves endocrine and metabolic disorders in obese rats primed by early weaning. Eur J Nutr .

145. Arçari DP, Bartchewsky W Jr, dos Santos TW, Oliveira KA, DeOliveira CC, et al. (2011) Anti-inflammatory effects of yerba maté extract (Ilex paraguariensis) ameliorate insulin resistance in mice with high fat diet-induced obesity. Mol Cell Endocrinol 335: 110-115.

146. Marchal J, Blanc S, Epelbaum J, Aujard F, Pifferi F (2012) Effects of chronic calorie restriction or dietary resveratrol ementation on insulin sensitivity markers in a primate, Microcebus murinus. PLoS One 7: e34289.

147. Franco JG, Lisboa PC, Lima NS, Amaral TA, Peixoto-Silva N, et al (2013) Resveratrol attenuates oxidative stress and prevents steatosis and hypertension in obese rats programmed by early weaning. J Nutr Biochem 24: 960-966.

148. Minakawa M, Kawano A, Miura Y, Yagasaki K (2011) Hypoglycemic effect of resveratrol in type 2 diabetic model $\mathrm{db} / \mathrm{db}$ mice and its actions in cultured L6 myotubes and RIN-5F pancreatic $~^{2}$-cells. J Clin Biochem Nutr 48: 237-244.

149. Torres MR, Ferreira Tda S, Carvalho DC, Sanjuliani AF (2011) Dietary calcium intake and its relationship with adiposity and metabolic profile in hypertensive patients. Nutrition 27: 666-671.

150. Nobre JL, Lisboa PC, Lima Nda S, Franco JG, Nogueira Neto JF, et al. (2012) Calcium ementation prevents obesity, hyperleptinaemia and hyperglycaemia in adult rats programmed by early weaning. Br J Nutr 107: 979-988.

151. Nobre JL, Lisboa PC, Santos-Silva AP, Lima NS, Manhães AC, et al. (2011) Calcium ementation reverts central adiposity, leptin, and insulin resistance in adult offspring programed by neonatal nicotine exposure. J Endocrinol 210 : 349-359.
This article was originally published in a special issue, Type 2 Diabetes Mellitus- Disease, Diagnosis \& Treatment handled by Editors. Dr. Judit Bene, University of Pécs, Hungary; Eun Seok Kang, Yonsei University College of Medicine, Korea 